\title{
儿茶素诱导的拟南芥根细胞膜脂变化”
}

\author{
郑国伟 ${ }^{1}$ ，陈 佳 ${ }^{2}$ ，李唯奇 ${ }^{1^{* *}}$ \\ (1 中国科学院昆明植物研究所中国西南野生生物种质资源库, 云南 昆明 650201 ; \\ 2 云南瑞升烟草技术 (集团) 有限公司, 云南昆明 650106)
}

\begin{abstract}
摘要：儿茶素是一种可以短时间内杀死植物细胞的植物毒素, 由于具有强的植物毒性, 儿茶素是开发除草 剂的理想化合物, 它可以诱导植物根系统的死亡。为了研究植物根细胞膜脂对化学胁迫的响应规律, 我们 运用高通量的脂类组学方法检测了拟南芥根中膜脂分子的组成, 比较了儿茶素处理下拟南芥野生型 (WS) 及磷脂酶 $\mathrm{D} \delta$ 缺失突变体 (PLD $-\mathrm{K} O)$ 根中膜脂分子的组成情况、膜脂含量、双键指数及碳链长度值。结 果发现，儿茶素处理拟南芥根 $90 \mathrm{~min}$ 后，二半乳糖基二酰甘油（DGDG）、单半乳糖基二酰甘油（MG$D G) 、$ 磷脂酰甘油 $(P G)$ 、磷脂酰胆碱 $(P C)$ 及磷脂酰肌醇 (PI) 的总含量在 WS 与 PLD $-K O$ 植株根中 都显著下降, 磷脂酰乙醇胺 (PE) 和磷脂酰丝氨酸 (PS) 在 WS 中下降, 在 PLD $\delta-K O$ 中上升。儿茶素处 理导致 PLD -KO 植株的 PC/PE 比值显著下降, WS 植株 PS 碳链长度显著增加。上述结果说明儿茶素处理 后，磷脂酶 D $\delta$ 缺失突变体膜不稳定性增加，PLD $\delta-K O$ 植株对儿茶素胁迫更加敏感。
\end{abstract}

关键词: 植物毒素; 脂类组学; 儿茶素; 拟南芥

中图分类号：Q945 文献标识码：A

文章编号 : 2095-0845(2012)04-383-08

\section{Profiling of Membrane Lipids of Arabidopsis Roots during Catechin Treatment}

\author{
ZHENG Guo-Wei ${ }^{1}$, Chen Jia ${ }^{2}$, LI Wei-Qi ${ }^{1 * *}$ \\ (1 The Germplasm Bank of Wild Species, Kunming Institute of Botany, Chinese Academy of Sciences, Kunming 650201, China; \\ 2 Yunnan Reascend Tobacco Technology (Group) CO., LTD., Kunming 650106, China)
}

\begin{abstract}
Catechin is a kind of phytotoxin and can kill plant cells in an hour. It can be developed as herbicide to kill weeds due to its strong phytotoxic activity. The main effect of this chemical is to trigger the death of the root system. To understand the response of root cell membrane lipids to catechin stress, we used the lipidomics approach to study the profiles of Arabidopsis root lipids molecules under catechin treatment. The changes of molecular species in membrane lipids, content of membrane lipids, double bond index (DBI) and acyl chain carbon number of the fatty

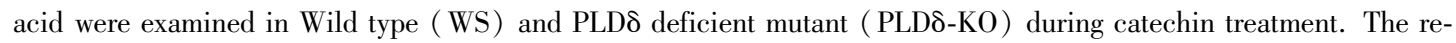
sults indicated that after 90 min treatment with catechin, the lipid contents of digalactosyldiacylglycerol (DGDG), monogalactosyldiacylglycerol (MGDG), phosphatidylglycerol (PG), phosphatidylcholine (PC), and phosphatidyli-

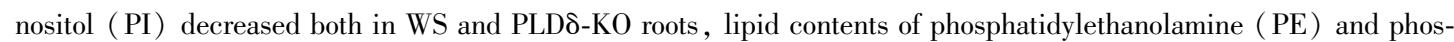
phatidylinositol (PS) decreased in WS roots, but increase in PLDS-KO roots, lipid contents of (phosphatidic acid) PA increased at the begin of treatment and declined to the level of control in WS roots. The ratio of the two major lipids in roots, PC and PE, declined significantly in PLD $\delta-K O$ plants, the acyl carbon number of PS in WS plants
\end{abstract}

* Foundation items: Fund of State Key Laboratory of Phytochemistry and Plant Resources in West China (0807B01211), West Light Foundation of the Chinese Academy Sciences

** Author for correspondenc; E-mail : weiqili@ mail. kib. ac. cn Received date: 2012-01-12, Accepted date: 2012-02-15

作者简介: 郑国伟 (1982-) 男, 博士, 助理研究员, 主要从事植物逆境分子生理学研究。E-mail: gwzheng@ mail. kib. ac. cn 
increased. The results suggested that PLD $\delta-K O$ is more sensitive than WS during catechin treatment, and suppression of PLD $\delta$ exacerbated membrane damage induced by catechin.

Key words: Phytotoxin; Lipidomics; Catechin; Arabidopsis

\begin{abstract}
Abbreviation: electrospray ionization tandem mass spectrometry, ESI-MS/MS; phosphatidylcholine, PC; phosphatidylethanolamine, PE; phosphatidylglycerol, PG; phosphatidic acid, PA; phosphatidylinositol, PI; phosphatidylserine, PS; digalactosyldiacylglycerol, DGDG; monogalactosyldiacylglycerol, MGDG; PLD, phospholipase D
\end{abstract}

Catechin is a common compound in plants which has antioxidant activity (Lee et al., 2002; Lu et al., 2011; Ma et al., 2003; Meyer et al., 1998; Ono et al., 1998; Su et al., 2002; Vuong et al., 2011; Yang et al., 2003). However, recent researches were focused on the phytotoxic and antibacterial activity of catechin that released from some plants to help them compete with surrounding plants. For example, Inderjit et al. (2008) found that catechin can significantly inhibit root growth of Bambusa and Koeleria seedlings; Bais et al. (2003) reported that catechin can inhibit seed germination of 6 kinds of weeds and crops; a study by $\mathrm{D}^{\prime}$ Abrosca et al. (2006) displayed that $(-)$-catechin can inhibit green alga Selenastrum capricornutum growth; (+)-catechin from seed coat of Sesbania virgata and velvetleaf can inhibit root elongation of Arabidopsis, cress, radish and soybean (Paszkowski and Kremer, 1988; Simões et al., 2008 ). Weir et al. (2006) reported that catechin treatment could cause Arabidopsis lipid peroxidation and inhibited plant growth. Catechin may be developed as a powerful herbicide to kill weeds due to its strong phytotoxic effects on roots. However, little is known about precise mode of action of catechin and the response of plant cell membrane lipids to catechin stress.

Membranes, particularly plasma and chloroplast membranes, are sensitive to environmental stimuli, the membrane lipids is crucial in plants response to stresses. PA is an important second messenger, it involves in plant response to various stresses (Testerink and Munnik, 2005; Wang, 2004, 2005b; Wang et al., 2006), and its level increases within minutes under these stresses (Munnik, 2001). PC and $\mathrm{PE}$ are related to the membrane stabilization (Welti et al., 2002; Yeagle et al., 1976). We found that through remodeling of membrane lipids plants respond to frequent alterations between high and low temperatures (Zheng et al., 2011). Phospholipase D ( PLD) hydrolyzes phospholipids to generate PA. PLD $\delta$ is one of the 12 PLDs in Arabidopsis, and it involves in plants stress response and PLD $\delta$ increases during stress ( Wang, 2005a). Zhang et al. ( 2003 ) found that PLD $\delta$-null cells displayed increased sensitivity to $\mathrm{H}_{2} \mathrm{O}_{2}$-induced cell death. PLD $\delta$-mediated hydrolysis of phospholipids plays a positive role in the plant response to oxidative stress. Li et al. (2004) found that PLD $\delta-K O$ plants exhibited less tolerance to freezing injuries whereas PLD $\delta$ OE plants exhibited more tolerance. PLD $\delta$ and PA signaling may involve in the response of plants to drought and salinity (Hong et al., 2010). However, under chemical stresses, like catechin, the change of lipid and the effects of PLD $\delta$ during this stress have not previously been described.

Plant lipidomics based on ESI-MS/MS can tell us the 11 classes of lipid changes under certain conditions ( Welti et al., 2002). The purpose of this study was to use lipidomics and Arabidopsis PLDઈ mutant to determine: (1) harmful effects of catechin to Arabidopsis root membrane lipid composition and (2) involvement of PLD $\delta$ in root membrane lipid profiling.

\section{Materials and methods}

\subsection{Plant materials and chemicals}

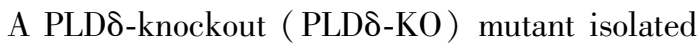
from Arabidopsis (Wassilewskija ecotype (WS )) was from Dr. Xuemin Wang's Laboratory previously; the loss of PLD $\delta$ was confirmed by the absence of the transcript, protein, and activity of PLD $\delta$ (Zhang et al., 2003). ( \pm )-catechin and (+)-cate- 
chin were purchased from Sigma-Aldrich ( C1788, C1251 respectively).

\subsection{Plant growth and treatments}

Seeds of two Arabidopsis genotypes were sterilized with ethanol (75\%) for 2 min and sodium hypochlorite ( $5 \%$ ) for $2 \mathrm{~min}$, and then rinsed three times with sterile distilled water. Surface-sterilized seeds were cold stratified for 2 days at $4{ }^{\circ} \mathrm{C}$, and then sowed on 1/2 MS medium (Murashige and Skoog, 1962) for hydroponic culture as described by Tocquin et al. (2003). The conditions of the growth chamber were $23 / 18{ }^{\circ} \mathrm{C}$, a $12 / 12 \mathrm{~h}$ light/dark cycle, and $120 \mu \mathrm{mol} \cdot \mathrm{m}^{-2} \mathrm{~s}^{-1}$ photosynthetic photon flux density.

We used 40 day old hydroponic seedlings to test the effects of catechin on Arabidopsis roots. Catechin was added to the hydroponic solutions to the concentration of $150 \mathrm{mg} \cdot \mathrm{L}^{-1}$, and hold for $0,10,30,90$ min. Roots were harvested for lipids analysis at each time.

\subsection{Lipid extraction and ESI-MS/MS analysis}

The process of lipid extraction, ESI-MS/MS analysis, and quantification was performed as described previously with minor modifications (Devaiah et al., 2006; Welti et al., 2002). Briefly, the roots were cut at sampling time and, to inhibit lipolytic activities, were transferred immediately into $3 \mathrm{~mL}$ of isopropanol with $0.01 \%$ butylated hydroxytoluene at $75{ }^{\circ} \mathrm{C}$. The roots were extracted with chloroform/ methanol (2:1) two additional times with 3 day of agitation each time. The remaining plant roots were heated overnight at $105{ }^{\circ} \mathrm{C}$ and weighed. The weights of these extracted and dried tissues were described as "dry weight" of the plants. Lipid samples were analyzed on a triple quadrupole MS/MS equipped for ESI. Data processing was performed as previously described (Devaiah et al., 2006; Welti et al., 2002).

\section{4 Data analysis}

Statistical analysis was performed using Origin 7.0 (OriginLab Corporation, Northampton, MA, USA). Double bond index (DBI) were calculated with the formula: $\mathrm{DBI}=\left[\sum\left(N_{1} \times \mathrm{mol} \%\right.\right.$ lipid $\left.)\right] / 100$, where
$N_{1}$ was the total number of double bonds in the two fatty acid chains of each glycerolipid molecule (Zheng et al., 2011). Average carbon number ( C) of acyl chains of lipid classes were calculated by the formula: $\mathrm{C}=\left[\sum\left(N_{2} \times \operatorname{mol} \%\right.\right.$ lipid $\left.)\right] / 100$, where $N_{2}$ was the total acyl carbons in each lipid molecule.

\section{Results and discussion}

\subsection{Root lipids profiling of Arabidopsis during catechin treatment}

To test the effects of catechin on Arabidopsis root membrane lipids, we used a lipidomics approach to profile changes in molecular species of membrane glycerolipids in Arabidopsis during catechin treatment. We identified and quantified about 120 glycerolipids molecular species including 11 species of lipids in Arabidopsis roots during catechin treatment (Figs. 1-3). The lipid profile of root is different from that of leaf, where PC and PE are the main lipids of root. The major lipid molecules of MGDG were 34:6MGDG and 36:6MGDG, in roots the content of $36: 6 \mathrm{MGDG}$ was a bit more than 34 : 6MGDG, but in leaves the content of $34: 6 \mathrm{MGDG}$ was much more than 36:6MGDG ( Li et al., 2008) ( our unpublished data).

To assess the role of PLD $\delta$ in Arabidopsis response to catechin, we employed the PLD $\delta$ knockout mutant Arabidopsis and compared its lipid profiles to that of wild type plants during catechin treatment. In wild type (WS) Arabidopsis plants, the content of total lipids decreased with the time of catechin treatment. After $90 \mathrm{~min}$ treatment with catechin, the content of DGDG, MGDG, PG, PC, and PI decreased both in WS and PLD $\delta-K O$ roots, PE and PS decreased in WS but increased in PLD $\delta-K O$ plants (Fig. 1). PA is an important secondary messenger in response of plants to abiotic stresses. It can increase in minutes after stimuli and then decreases to the levels of control (Wang et al., 2006). In out experiment, PA rose at the begin of catechin treatment and declined to the level of the control after 90 min treatment in wild plants. While in PLD $\delta-K O$ 
plants, PA decreased during the catechin treatments (Fig. 1). PLD $\delta$ can hydrolyze phospholipids to PA (Zhang et al., 2003 ), and suppression of PLD $\delta$ leads no PA increase during catechin treatment. We thought that PLD $\delta$ derived PA was very important for Arabidopsis response to catechin stress.

The total content of LysoPLs was a bit different in the two plants. Detailed analysis of the lipid profiles indicated that changes in the phospholipids and galactolipids in the two plants were similar during catechin treatment (Fig. 2, 3), except for minor differences in PE species $34: 2,34: 3$, and $36: 5$ (total acyl chains: double bonds), in PA species $34: 2$, 34:3, and 36:5 (Fig. 2), and in lysophospholipids and lysoPC species 18:2 and 18:3 (Fig. 3 ).

\section{2 PC and PE ratio reduced in PLDo-KO under catechin stress}

$\mathrm{PC}$ and $\mathrm{PE}$ are related to the stabilization of membrane. Unsaturated PEs have strong propensity to form hexagonal phases (Cullis and Hope, 1978 ) which might lead to the formation of a nonbilayer lipid phase and disturb the membrane integrity and cell function, whereas PC is a bilayer-stabilizing lipid (Welti et al., 2002). The molar ratio of PC/PE, which implies the membrane stabilization, tends to drop in plants under cold and hydration stress (Hazei and Williams, 1990; Welti et al., 2002 ).

To assess the membrane stabilization of Arabidopsis during catechin treatment, we calculated PC and PE ratio of this process. We found that both $\mathrm{PC}$ and $\mathrm{PE}$ decreased during catechin treatment in WS, whereas the content of PC decreased and PE increased during

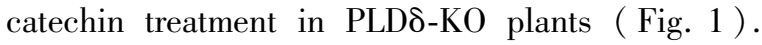
The ratio of $\mathrm{PC} / \mathrm{PE}$ in $\mathrm{WS}$ did not change too much during catechin treatment, however, the $\mathrm{PC} / \mathrm{PE}$ ratio in PLD $\delta-K O$ plants dropped from 1.18 to 0.92 after 90 min of catechin treatment (Table 1 ). The results suggested that PLD $\delta$ play an important role in maintaining membrane stabilization in catechin induced Arabidopsis membrane disturbance.

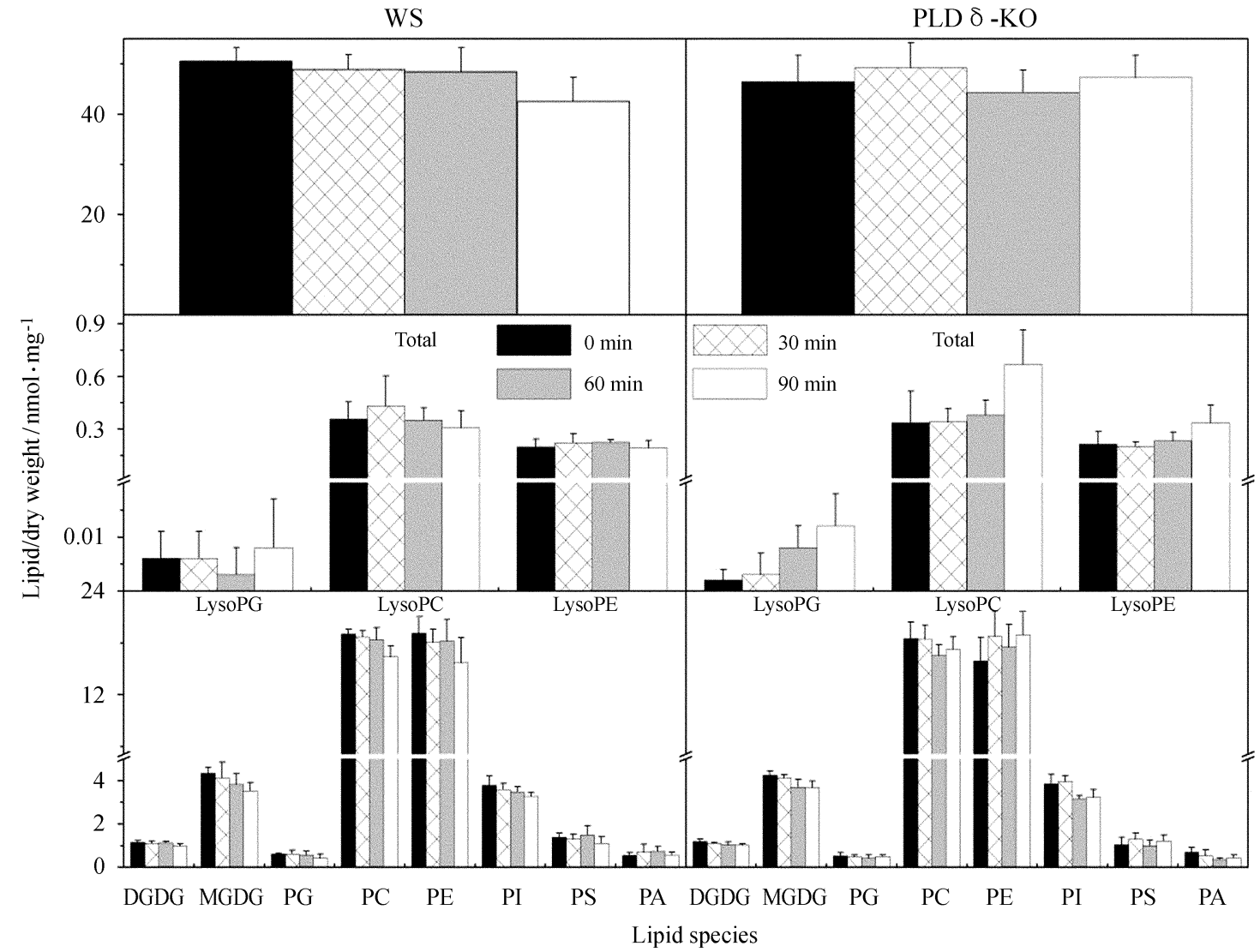

Fig. 1 Changes of each head group class and total lipids in WS and PLD $\delta-K O$ plants during catechin treatment. Values are means $\pm S . D$. ( $n=5$ ) 


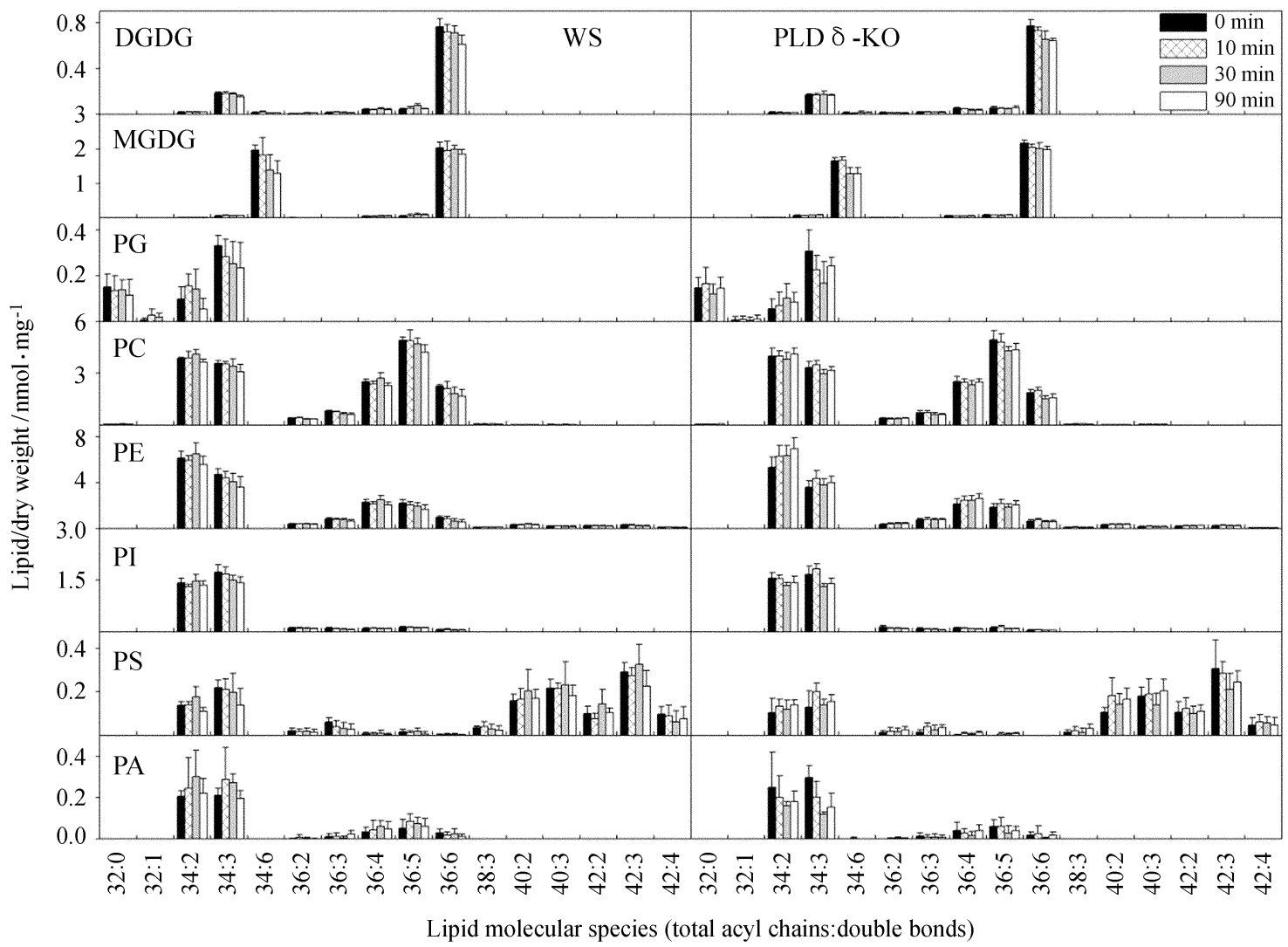

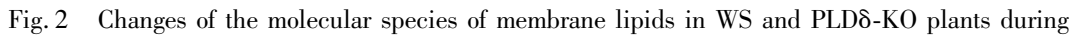
different time of catechin treatment. Values are means $\pm S . D . \quad(n=5)$

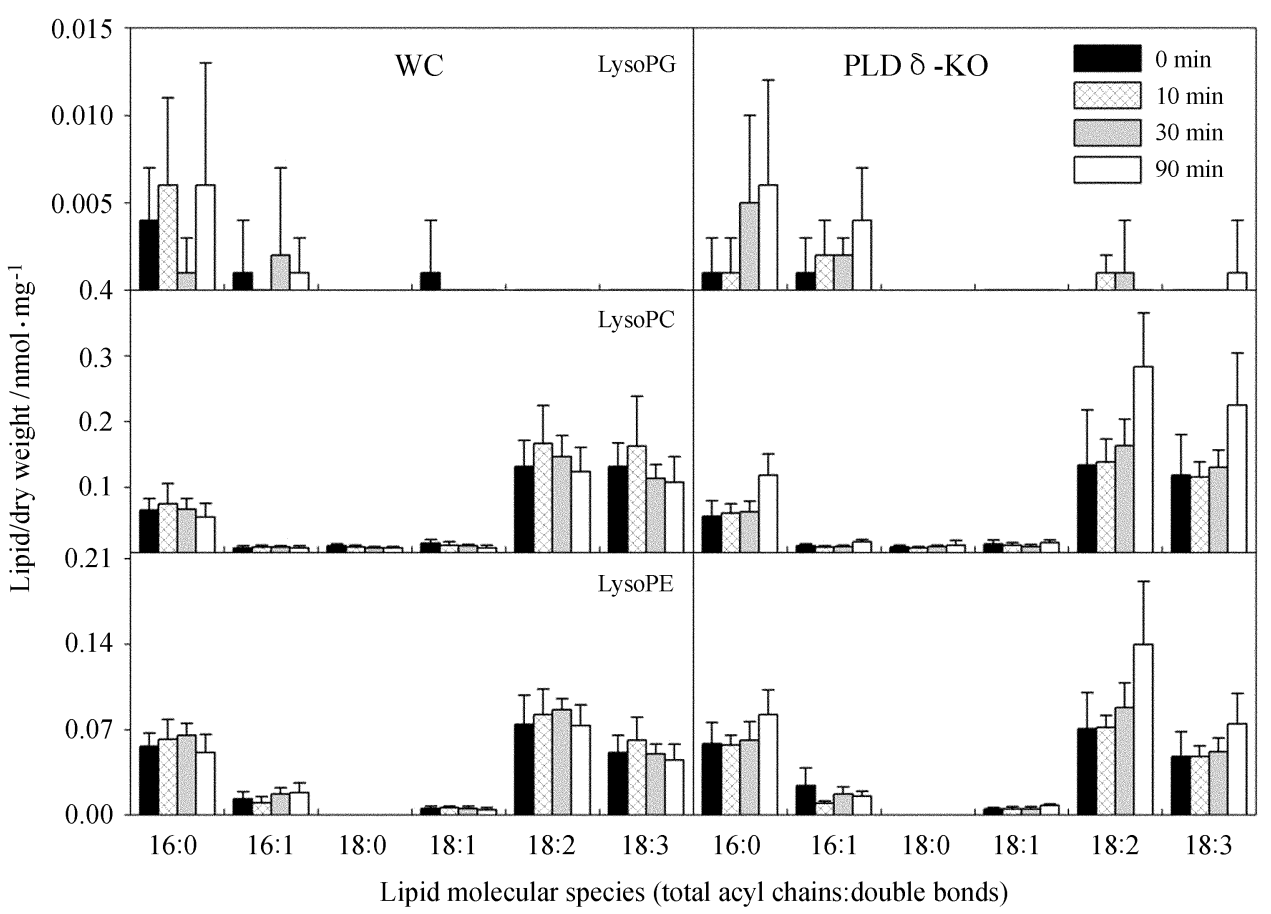

Fig. 3 Changes of the molecular species of lysophospholipids in WS and PLD $\delta$-KO plants during different time of catechin treatment. Values are means \pm S. D. $\quad(n=5)$ 
Table 1 Lipid ratio of WS and PLD - KO plants during catechin treatment. An asterisk indicates that the value is different from control $(P<0.05)$. Values are means $\pm S D(n=5)$

\begin{tabular}{|c|c|c|c|c|c|}
\hline \multirow{2}{*}{ Lipids } & \multirow{2}{*}{ Plants } & \multicolumn{4}{|c|}{ Lipid ratio } \\
\hline & & $0 \mathrm{~min}$ & $10 \mathrm{~min}$ & $30 \mathrm{~min}$ & 90 min \\
\hline \multirow{2}{*}{$\mathrm{PC} / \mathrm{PE}$} & WS & $1.00 \pm 0.07$ & $1.04 \pm 0.06$ & $1.02 \pm 0.09$ & $1.06 \pm 0.13$ \\
\hline & 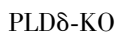 & $1.18 \pm 0.12$ & $0.99 \pm 0.08 *$ & $0.95 \pm 0.09 *$ & $0.92 \pm 0.09 *$ \\
\hline \multirow{2}{*}{$(\mathrm{PC}+\mathrm{PE}) /$ Total } & WS & $0.75 \pm 0.01$ & $0.75 \pm 0.02$ & $0.76 \pm 0.01$ & $0.76 \pm 0.02$ \\
\hline & 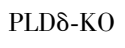 & $0.74 \pm 0.02$ & $0.75 \pm 0.02$ & $0.77 \pm 0.01 *$ & $0.76 \pm 0.02$ \\
\hline \multirow{2}{*}{ Glycolipids/Total } & WS & $0.11 \pm 0.01$ & $0.11 \pm 0.01$ & $0.10 \pm 0.01$ & $0.11 \pm 0.01$ \\
\hline & PLDઈ-KO & $0.12 \pm 0.01$ & $0.11 \pm 0.01$ & $0.11 \pm 0.01$ & $0.10 \pm 0.01 *$ \\
\hline
\end{tabular}

\section{3 The influence of catechin to lipid double}

\section{bond index and acyl chain lengths}

Maintaining the integrity and optimal fluidity of the membranes is very important to organisms. Changing in the degree of lipid unsaturation and the number lipid acyl chain carbon could influence the integrity and fluidity of membranes. We got the mol\% content of each lipid molecule species based on the data of $\mathrm{nmol} / \mathrm{mg}$ dry weight, and calculated the DBI and Carbon number of acyl chains of each lipid species.
We found that unlike the DBI of leaves, total lipid DBI of roots was about 3.5, but in leaves the DBI was about 4.1 (Zheng et al., 2011) (Table 2 ), because the main lipid constituent in root are PC and PE which have less double bond than MGDG and DGDG which was the main lipid in leaves. The degree of unsaturation of root membrane lipids is less than leaves, the DBI of PG in roots was about 1.2 less than in roots, the DBI of MGDG, DGDG, and PS was a bit less than that in leaves ( $\mathrm{Li}$ et al., 2011 ) ( Table 2). The DBI decreased as the catechin

Table 2 Double bond index (DBI) of membrane during catechin treatment in WS and PLD $\delta$-KO plants. An asterisk indicates that the value is different from control $(P<0.05)$. Values are means $\pm S D(n=5)$

\begin{tabular}{|c|c|c|c|c|c|}
\hline \multirow{2}{*}{ Lipid species } & \multirow{2}{*}{ Plants } & \multicolumn{4}{|c|}{ Double bond index } \\
\hline & & Control & $10 \mathrm{~min}$ & $30 \mathrm{~min}$ & $90 \mathrm{~min}$ \\
\hline \multirow{2}{*}{ DGDG } & WS & $5.14 \pm 0.04$ & $5.12 \pm 0.03$ & $5.08 \pm 0.05$ & $5.06 \pm 0.02 *$ \\
\hline & 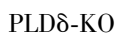 & $5.13 \pm 0.04$ & $5.15 \pm 0.04$ & $5.08 \pm 0.05$ & $5.08 \pm 0.06$ \\
\hline \multirow{2}{*}{ MGDG } & WS & $5.83 \pm 0.02$ & $5.81 \pm 0.07$ & $5.78 \pm 0.03^{*}$ & $5.77 \pm 0.05$ * \\
\hline & 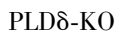 & $5.79 \pm 0.02$ & $5.80 \pm 0.01$ & $5.77 \pm 0.02$ & $5.77 \pm 0.02$ \\
\hline \multirow{2}{*}{ PG } & WS & $2.02 \pm 0.23$ & $1.96 \pm 0.31$ & $1.92 \pm 0.26$ & $2.04 \pm 0.17$ \\
\hline & 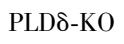 & $2.03 \pm 0.20$ & $1.82 \pm 0.32$ & $1.66 \pm 0.37$ & $1.82 \pm 0.18$ \\
\hline \multirow{2}{*}{$\mathrm{PC}$} & WS & $3.76 \pm 0.02$ & $3.75 \pm 0.11$ & $3.71 \pm 0.04 *$ & $3.71 \pm 0.07$ \\
\hline & PLDS-KO & $3.74 \pm 0.01$ & $3.75 \pm 0.02$ & $3.68 \pm 0.05^{*}$ & $3.65 \pm 0.02 *$ \\
\hline \multirow{2}{*}{$\mathrm{PE}$} & WS & $3.14 \pm 0.01$ & $3.12 \pm 0.05$ & $3.05 \pm 0.06^{*}$ & $3.04 \pm 0.05$ * \\
\hline & PLD反-KO & $3.11 \pm 0.02$ & $3.11 \pm 0.01$ & $3.04 \pm 0.02 *$ & $3.03 \pm 0.02 *$ \\
\hline \multirow{2}{*}{ PI } & WS & $2.69 \pm 0.03$ & $2.71 \pm 0.04$ & $2.66 \pm 0.06$ & $2.67 \pm 0.03$ \\
\hline & 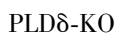 & $2.65 \pm 0.01$ & $2.69 \pm 0.03 *$ & $2.64 \pm 0.02$ & $2.63 \pm 0.01$ * \\
\hline \multirow{2}{*}{ PS } & WS & $2.79 \pm 0.04$ & $2.77 \pm 0.10$ & $2.67 \pm 0.11$ & $2.69 \pm 0.10$ \\
\hline & 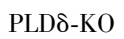 & $2.71 \pm 0.06$ & $2.69 \pm 0.08$ & $2.68 \pm 0.04$ & $2.67 \pm 0.04$ \\
\hline \multirow{2}{*}{$\mathrm{PA}$} & WS & $3.02 \pm 0.16$ & $3.06 \pm 0.17$ & $2.99 \pm 0.13$ & $2.99 \pm 0.16$ \\
\hline & 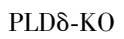 & $2.97 \pm 0.07$ & $3.01 \pm 0.22$ & $2.75 \pm 0.25$ & $2.98 \pm 0.09$ \\
\hline \multirow{2}{*}{ Total Lipids } & WS & $3.58 \pm 0.01$ & $3.56 \pm 0.08$ & $3.49 \pm 0.07$ & $3.51 \pm 0.05$ \\
\hline & 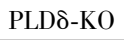 & $3.58 \pm 0.03$ & $3.55 \pm 0.02$ & $3.49 \pm 0.03 *$ & $3.44 \pm 0.04 *$ \\
\hline
\end{tabular}


treatment, and there was no difference in DBI between

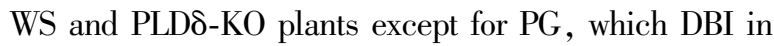

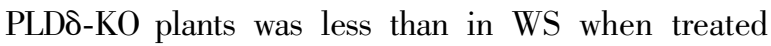
with catechin ( Table 2 ). These results suggested that catechin may induce membrane lipids oxidation.

In the eight classes of lipids that calculated acyl chain carbons, the acyl chain carbons of MGDG of roots was longer than that in leaves (Table 3, our unpublished data). The longest acyl chain was PS which was about 39 carbons ( Table 3 ). Under catechin treatment, the acyl chain carbons of the lipids change little except that of PS which in WS increased 0.4 and in PLD $\delta-K O$ decreased 0.66 after 90 min of catechin treatment. Catechin could induce change of length of lipid acyl chain, the most sensitive lipid is PS.

Table 3 The acyl chain carbon of membrane lipids during catechin treatment in WS and PLD $\delta$-KO plants. An asterisk indicates that the value is different from control $(P<0.05)$. Values are means $\pm S D(n=5)$

\begin{tabular}{|c|c|c|c|c|c|}
\hline \multirow{2}{*}{ Lipid species } & \multirow{2}{*}{ Plants } & \multicolumn{4}{|c|}{ Acyl chain carbon $(\mathrm{C})$} \\
\hline & & Control & $10 \mathrm{~min}$ & $30 \mathrm{~min}$ & $90 \mathrm{~min}$ \\
\hline \multirow{2}{*}{ DGDG } & WS & $35.54 \pm 0.02$ & $35.53 \pm 0.02$ & $35.56 \pm 0.02$ & $35.54 \pm 0.03$ \\
\hline & PLD $\delta-K O$ & $35.59 \pm 0.02$ & $35.59 \pm 0.02$ & $35.53 \pm 0.03 *$ & $35.53 \pm 0.03^{*}$ \\
\hline \multirow{2}{*}{ MGDG } & WS & $35.00 \pm 0.03$ & $35.03 \pm 0.09$ & $35.16 \pm 0.11^{*}$ & $35.15 \pm 0.11^{*}$ \\
\hline & 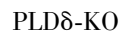 & $35.10 \pm 0.01$ & $35.08 \pm 0.02$ & $35.18 \pm 0.04^{*}$ & $35.17 \pm 0.04 *$ \\
\hline \multirow{2}{*}{ PG } & WS & $33.47 \pm 0.20$ & $33.46 \pm 0.22$ & $33.40 \pm 0.17$ & $33.47 \pm 0.14$ \\
\hline & PLD $\delta-K O$ & $33.42 \pm 0.09$ & $33.31 \pm 0.23$ & $33.31 \pm 0.25$ & $33.37 \pm 0.19$ \\
\hline \multirow{2}{*}{ PC } & WS & $35.20 \pm 0.02$ & $35.19 \pm 0.05$ & $35.17 \pm 0.01^{*}$ & $35.16 \pm 0.02 *$ \\
\hline & PLD $\delta-K O$ & $35.20 \pm 0.01$ & $35.18 \pm 0.01 *$ & $35.17 \pm 0.03$ & $35.14 \pm 0.02 *$ \\
\hline \multirow{2}{*}{$\mathrm{PE}$} & WS & $35.22 \pm 0.02$ & $35.21 \pm 0.04$ & $35.16 \pm 0.05^{*}$ & $35.16 \pm 0.03 *$ \\
\hline & PLD $\delta-K O$ & $35.22 \pm 0.02$ & $35.20 \pm 0.02$ & $35.16 \pm 0.01 *$ & $35.15 \pm 0.01 *$ \\
\hline \multirow{2}{*}{ PI } & WS & $34.29 \pm 0.03$ & $34.29 \pm 0.02$ & $34.26 \pm 0.01$ & $34.27 \pm 0.02$ \\
\hline & 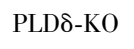 & $34.29 \pm 0.03$ & $34.26 \pm 0.03$ & $34.28 \pm 0.02$ & $34.24 \pm 0.03^{*}$ \\
\hline \multirow{2}{*}{ PS } & WS & $38.76 \pm 0.12$ & $38.75 \pm 0.18$ & $38.88 \pm 0.45$ & $39.16 \pm 0.38$ \\
\hline & PLD $\delta-K O$ & $39.48 \pm 0.46$ & $38.89 \pm 0.13^{*}$ & $38.93 \pm 0.55$ & $38.82 \pm 0.31 *$ \\
\hline \multirow{2}{*}{$\mathrm{PA}$} & WS & $34.45 \pm 0.17$ & $34.50 \pm 0.10$ & $34.45 \pm 0.07$ & $34.53 \pm 0.11$ \\
\hline & 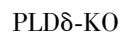 & $34.36 \pm 0.15$ & $34.43 \pm 0.13$ & $34.33 \pm 0.20$ & $34.47 \pm 0.13$ \\
\hline \multirow{2}{*}{ Total Lipids } & WS & $35.20 \pm 0.02$ & $35.19 \pm 0.04$ & $35.19 \pm 0.05$ & $35.18 \pm 0.03$ \\
\hline & 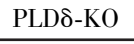 & $35.19 \pm 0.02$ & $35.19 \pm 0.03$ & $35.17 \pm 0.04$ & $35.16 \pm 0.02 *$ \\
\hline
\end{tabular}

In conclusion, the results of this study suggested that PLD $\delta$ deficient plant was more sensitive to catechin stress than wild plant. Catechin could induce the root lipids change and lead to the membrane disturbance. However, many questions, such as the mechanisms of different lipid profiles in roots and leaves; the role of PLD $\delta$ play in Arabidopsis resist to catechin stress; and the reason of changes of acyl chain carbon length to catechin stress, remained unclear and would be further studied in the future.

Acknowledgement: We thank Dr. Hongyin Chen, Dr. Bo Tian and Dr. Yanxia Jia for their critical reading of the paper.

\section{References :}

Bais HP, Walker TS, Kennan AJ et al., 2003. Structure-dependent phytotoxicity of catechins and other flavonoids : flavonoid conversions by cell-free protein extracts of Centaurea maculosa ( spotted knapweed) roots $[\mathrm{J}]$. Journal of Agricultural and Food Chemistry, 51 (4) : 897-901

Cullis PR, Hope MJ, 1978. Effects of fusogenic agent on membrane structure of erythrocyte ghosts and the mechanism of membrane fusion [J]. Nature, 271 (5646) : 672-674

D'Abrosca BD, Dellagreca M, Fiorentino A et al., 2006. Chemical constituents of the aquatic plant Schoenoplectus lacustris: Evaluation of phytotoxic effects on the green alga Selenastrum capricornutum [J]. Journa of Chemical Ecology, 32 (1) : 81-96

Devaiah SP, Roth MR, Baughman E et al., 2006. Quantitative profiling of polar glycerolipid species from organs of wild-type Arabi- 
dopsis and a PHOSPHOLIPASE D $\alpha 1$ knockout mutant [ J ]. Phytochemistry, 67 (17) : 1907-1924

Hazei JR, Williams EE, 1990. The role of alterations in membrane lipid compositon in enabling physiological adaptation of organisms to their physical environment [J]. Progress in Lipid Research, 29 (3) : $167-227$

Hong YY, Zhang WH, Wang XM, 2010. Phospholipase D and phosphatidic acid signalling in plant response to drought and salinity [J]. Plant Cell and Environment, 33 (4) : 627-635

Inderjit, Pollock JL, Callaway RM et al., 2008. Phytotoxic effects of $( \pm)$-catechin in vitro, in soil, and in the field $[\mathrm{J}]$. PLoS ONE, 3 ( 7) : e2536

Lee JS, Kim HJ, Park H et al., 2002. New diarylheptanoids from the stems of Carpinus cordata [J]. Journal of Natural Products, 65 (9) : $1367-1370$

Li WQ, Li MY, Zhang WH et al., 2004. The plasma membranebound phospholipase D $\delta$ enhances freezing tolerance in Arabidopsis thaliana $[\mathrm{J}]$. Nature Biotechnology, 22 (4) : 427-422

Li WQ, Wang R, Li MY et al., 2008. Differential degradation of extraplastidic and plastidic lipids during freezing and post-freezing recovery in Arabidopsis thaliana $[\mathrm{J}]$. Journal of Biological Chemistry, 283 (1) : 461-468

Li Y (李艳), Tian B (田波), Li WQ (李唯奇), 2011. Suppression of phospholipase $D \delta$ enhances the membrane damage induced by UV-B irradiation [J]. Plant Diversity and Resources (植物分类与资源学报), 33 (3) : 299-305

Lu NA, Chen PQ, Yang Q et al., 2011. Anti- and pro-oxidant effects of $(+)$-catechin on hemoglobin-induced protein oxidative damage [J]. Toxicology in Vitro, 25 (4) : 833-838

Ma J, Luo XD, Protiva P et al., 2003. Bioactive novel polyphenols from the fruit of Manilkara zapota (Sapodilla) $[\mathrm{J}]$. Journal of Natural Products, 66 ( 7) : 983-986

Meyer AS, Heinonen M, Frankel EN, 1998. Antioxidant interactions of catechin, cyanidin, caffeic acid, quercetin, and ellagic acid on human LDL oxidation [J]. Food Chemistry, 61 (1-2) : 71-75

Munnik T, 2001. Phosphatidic acid: an emerging plant lipid second messenger $[\mathrm{J}]$. Trends in Plant Science, 6 (5) : 227-233

Murashige T, Skoog F, 1962. A revised medium for rapid growth and bio assays with tobacco tissue cultures $[\mathrm{J}]$. Physiologia Plantarum, 15 (3) : 473-497

Ono K, Nakao M, Toyota M et al., 1998. Catechin production in cultured Polygonum hydropiper cells $[\mathrm{J}]$. Phytochemistry, 49 (7) : 1935-1939

Paszkowski WL, Kremer RJ, 1988. Biological activity and tentative identificatioin of flavonoid components in velvetleaf (Abutilon theophrasti Medik. ) seed coats [J]. Journal of Chemical Ecology, 14 (7) : 1573-1582

Simões K, Du J, Kretzschmar FS et al., 2008. Phytotoxic catechin leached by seeds of the tropical weed Sesbania virgata $[\mathrm{J}]$. Journa of Chemical Ecology, 34 (5) : 681-687

Su BN, Cuendet M, Hawthorne ME et al., 2002. Constituents of the bark and twigs of Artocarpus dadah with cyclooxygenase inhibitory activity [J]. Journal of Natural Products, 65 (2) : 163-169

Testerink C, Munnik T, 2005. Phosphatidic acid: a multifunctional stress signaling lipid in plants $[\mathrm{J}]$. Trends in Plant Science, 10 (8) : $368-375$

Tocquin P, Corbesier L, Havelange A et al., 2003. A novel high efficiency, low maintenance, hydroponic system for synchronous growth and flowering of Arabidopsis thaliana $[\mathrm{J}]$. BMC Plant Biology, 3 ( 1 ) : 2

Vuong QV, Stathopoulos CE, Nguyen MH et al., 2011. Isolation of green tea catechins and their utilization in the food industry [J]. Food Reviews International, 27 (3) : 227-247

Wang XM, 2004. Lipid signaling [ J]. Current Opinion in Plant Biology, 7 ( 3 ) : 329-336

Wang XM, 2005a. Phospholipase D in hormonal and stress signaling [J]. Current Opinion in Plant Biology, 5 (5) : 408-414

Wang XM, 2005b. Regulatory functions of phospholipase D and phosphatidic acid in plant growth, development, and stress responses [J]. Plant Physiology, 139 (2) : 566-573

Wang XM, Devaiah SP, Zhang WH et al., 2006. Signaling functions of phosphatidic acid [J]. Progress in Lipid Research, 45 (3): $250-278$

Weir TL, Bais HP, Stull VJ et al., 2006. Oxalate contributes to the resistance of Gaillardia grandiflora and Lupinus sericeus to a phytotoxin produced by Centaurea maculosa $[\mathrm{J}]$. Planta, 223 (4) : 785-795

Welti R, Li WQ, Li MY et al., 2002. Profiling membrane lipids in plant stress responses: Role of phospholipase dalpha in freezinginduced lipid changes in Arabidopsis [ $\mathrm{J}]$. Journal of Biological Chemistry, 277 (35) : 31994-32002

Yang H, Protiva P, Cui BL et al., 2003. New bioactive polyphenols from Theobroma grandiflorum ( “Cupuacu”) [ J ]. Journal of Nautral Product, 66 (11) : 1501-1504

Yeagle PL, Hutton WC, Huang CH et al., 1976. Structure in the polar head region of phospholipid bilayers: $A{ }^{31} \mathrm{P}\left\{{ }^{1} \mathrm{H}\right\}$ nuclear overhauser effect study $[\mathrm{J}]$. Biochemistry, $15(10): 2121-$ 2124

Zhang WH, Wang CX, Qin CX et al., 2003. The oleate-stimulated phospholipase D, PLD $\delta$, and phosphatidic acid decrease $\mathrm{H}_{2} \mathrm{O}_{2}$ induced cell death in Arabidopsis [J]. The Plant Cell, 15 (10) : 2285-2295

Zheng GW, Tian B, Zhang FJ et al., 2011. Plant adaptation to frequent alterations between high and low temperatures : remodelling of membrane lipids and maintenance of unsaturation levels $[\mathrm{J}]$. Plant Cell and Environment, 34 (9) : 1431-1442 